\title{
Development of a new machine system for the forming of micro-sheet- products
}

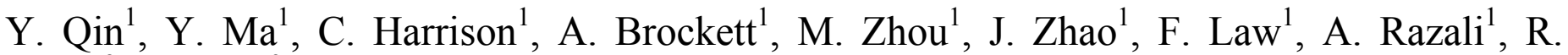
Smith $^{2}$, J. Eguia ${ }^{3}$

${ }^{1}$ DMEM, University of Strathclyde, Glasgow G1 1XJ, UK

URL: www.strath.ac.uk;www.masmicro.net e-mail:qin.yi@strath.ac.uk

${ }^{2}$ Pascoe Engineering Ltd. Glasgow, G53 7TB, UK

URL: $\underline{\text { www.pascoelimited.com }}$

e-mail: bob@pascoelimited.com

${ }^{3}$ Fundacion Tekniker, 20600 EIBAR, GIPUZKOA, Spain

URL: www.tekniker.es

e-mail:jeguia@tekniker.es

ABSTRACT: Challenges concerning industrial applications of microforming have been recognised, and efforts are being made to meet these challenges. For micro-sheet-forming, fundamentals related to the development of an industrial system are being examined further by the EU MASMICRO consortium, based on which a prototype micro-sheet-forming machine system has been developed. The system development addresses the specific issues concerning machine dynamics, material feeding, production rate, tool design and fabrication, and part transport. The prototype system has been tested with the forming of demonstration components and an industrial version of the machine has been designed.

Key words: Microforming, Micro-sheet-forming, Manufacturing system, Machine design

\section{MICRO-SHEET-FORMING - SOME ISSUES}

Miniature/micro sheet metal parts include electrical connectors and lead-frames, micro-meshes, microsprings, micro-cups, laminates for micro-motor and fluidic devices, micro-gears, casings/housings of micro-devices, micro-knifes, etc. The forming of these parts is of significant challenges, especially when the sizes/features reduce to such as tens or hundreds of microns or when the precision requirements of the formed parts reach certain levels, such as less than a few microns: these challenges having been subjected to a wide range of investigations [1-5].

One of main challenges remaining in microforming is to transfer the laboratory processes to the production lines of industry, for which the development of the manufacturing facilities is a key factor [4-7]. As far as micro-sheet-forming is concerned, the following are some particularities that need to be considered, especially in the forming of sheet materials of less than 100 microns thickness and feature sizes of sub-millimetres: (a) The selection of proper materials which are micro-formable (constraints to the forming limits, especially those influenced by the microstructures of the materials);

(b) Special care in the handling of thin materials and in the collection of scrap/parts which also matches the production-rate requirements;

(c) Constraints to the tool-design and lay-out due to the limited space, the closeness of the tool components and the fragility of the tools;

(d) Tool-fabrication capabilities (micro-features, precision, assembly, coating, etc.) and tool-cost;

(e) Miniaturisation of the forming equipment, and improvement in precision and design to maximise the work-space;

(f) Addressing spring-back and reducing and/or eliminating wrinkles, fractures, burrs, etc. associated with the forming of very thin sheet metal parts.

The development reported in this paper is one of the activities currently in the EU FP6 IP MASMICRO (www.masmicro.net), co-ordinated by the University of Strathclyde. 


\section{MACHINE DESIGN CONSIDERATIONS}

Micro-sheet-metal-parts may be formed using conventional, large-scale machines which may be optimised/upgraded especially for the manufacture of miniature/micro-components with enhanced precisions [1]. This may be achievable through using delicately designed and fabricated forming-tools and ram-guides. Machines of smaller size (bench-type machines) may also be built with newly-enhanced elements/parts and/or designs, particularly for micro-sheet-forming applications, e.g. using linear motors and/or piezo-electric actuators, combined with hydraulic or displacement-amplifying mechanisms, etc. Micro-forming may also be effected with miniature-/micro-machines. The machines in this category are of much smaller size, compared to that of conventional, large-scale presses. The development of this type of machine has attracted significant interest from researchers during the last fifteen years. Various new concepts have been explored to design and fabricate micromachine prototypes. An analysis of possible machines for micro-forming was provided in the literature [5].

In the current project, the development is targeted at industrially-applicable facilities. The following are considered for the development of the micro-sheetforming machine system: the machine design targets the forming of thin sheet parts (thickness $<100 \mu \mathrm{m}$ ); a modular design to enable easy set-up and changes of the force/power source, guides, feeder, part carrier, tooling and work space, if these are needed; the size effects relating to the materials, sheet feeding, guiding and holding (during the forming), scrap collection, tool-design, part transport, etc.; better monitoring of force and displacement for easier control; better safety and protection measures; environmentally friendly, bench-type, low-cost equipment for industry.

\section{MACHINE SYSTEM DEVELOPMENT}

\subsection{Machine dynamics}

In the early stages of the development, various machine-frame concepts were considered and examined in detail. The aim was to establish an "optimal" machine-frame concept, based on a comparative study of the machine static and dynamic characteristics, modular concepts, availability of the workspace, etc. The machine dynamics is a major issue, considering the impact of high-speed stamping on the bench-type machine design and that no direct connection between the machine and the bench is expected. FE analysis was carried out to examine the natural frequency of the machine system (Fig. 1) and the dynamic response of the tooling and the machine frame when subjected to high-speed stamping. The analysis served as a useful reference for the design of the machine, tooling and key assembly, this resulting in excellent dynamic performance being predicted for the machine system. Under high-speed working conditions (up to $1000 \mathrm{spm}$ in micro-stamping), the machine system remains stable.

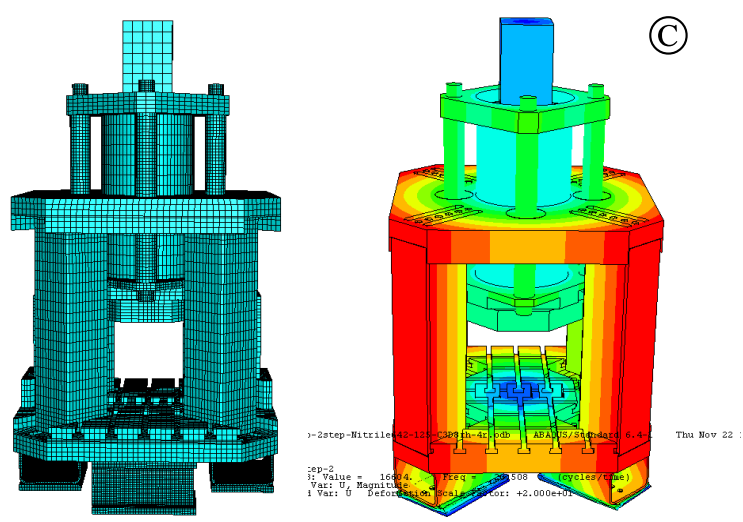

Fig. 1 Machine dynamics analysis with an FEM

\subsection{Tool development}

One of the weakest parts in the research into microforming was insufficiency in addressing tool-design which meets industrial needs. To scale-up the prototype processes to production, tool design is crucial. One of the key developments reported in this paper was qualification of the dynamics characteristics of micro-stamping-tools (Fig. 2). Such characteristics have a significant effect on the tool performance and the tool life. The latter was a major concern for microforming, due to the fragility of the tools, especially that of the punches. Dynamics analysis and experimental tests were performed for the tool-sets for industrial demonstrationsors. Especially, the dynamics response of the punches and the blank holders was examined carefully, due to its direct action on the material during forming. The key findings include delayed contacts with the strip and eccentric loads imposed on tools, which resulted in either not 
holding the strip properly or timely or damage of the tools due to the off-centre of the punch heads/tips.

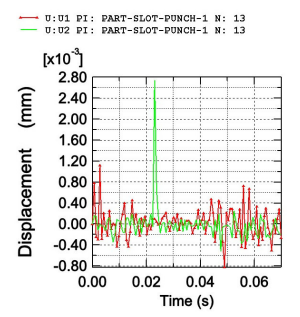

Rectangular punch

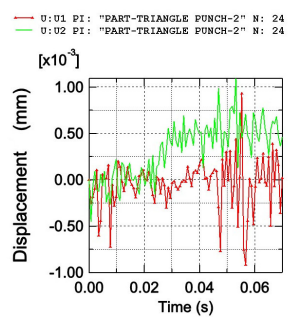

Triangular punch
Fig. 2 An example of the response of the punches

The tool-sets were designed with extra care for the blank-holder(s) which have significant roles in the forming of thin sheet micro-parts (particularly, considering timing, holding areas and the force). Tests were performed to examine the holding effectiveness relating to the prevention of the development of defects and the improvement of forming quality. Other developments included a new vacuum-system design and compressed-air-guidance design for parts/scrap collection. Fig. 3 illustrates one of the tool models developed.

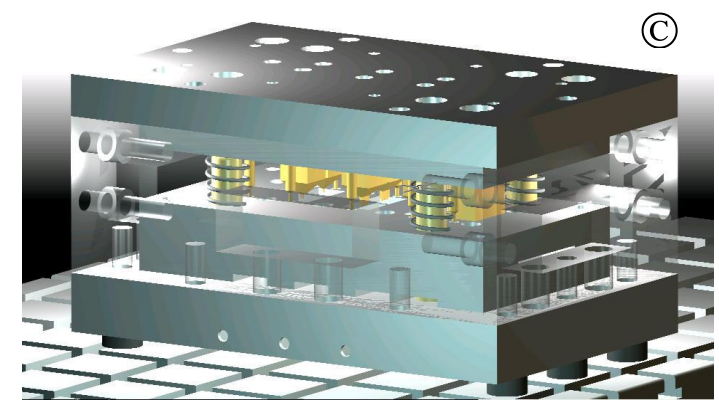

Fig. 3 A tool-set for micro-sheet-forming

\subsection{Material feeding}

Feeding thin strips at a high rate and with high accuracy is a challenge in micro-sheet-forming. A pneumatic feeder and a servo feeder with special attachments for strip guiding were tested for the feeding of thin metal strips (copper, brass, carbon and stainless steels), the thicknesses of which were between $20 \mu \mathrm{m}$ to $100 \mu \mathrm{m}$. Feeding rates of up to $1000 \mathrm{spm}$ are achieved. A feeding accuracy of 10 to $30 \mu \mathrm{m}$ is achievable, depending on the speed and feeding distance. Further improving the positional accuracy of the strip feeding is achieved by using pilot-pins. A new, linear-motor-driven strip feeder is being developed, with the objective of achieving a feeding precision (feeder alone) of less than $5 \mu \mathrm{m}$.

\subsection{Part transport - Transport-Micro ${ }^{T M}$}

The Transport-Micro ${ }^{T M}$ is a design developed at the University of Strathclyde for transporting the formed micro-parts directly out of the tool/die-set. A special tape-reel system is used to hold and transport the parts being formed. Surftape ${ }^{\circledR}$ was chosen as the carrying medium for this purpose. Using other types of tapes is also feasible. The part-carrying concept consists of an input and an output section which are constructed on, and around, the machine system developed. The alignment of the tape is critical for ensuring the success of transporting the parts being formed, which is achieved with proper mechanical alignment and the control being synchronised with the movement of the machine ram and strip feeding/pulling.

\subsection{The machine system - Flexible- $\mu$-Forming ${ }^{T M}$}

A machine system - Flexible- $\mu$-Forming ${ }^{T M}$ has been developed (Fig. 4) and is being refined. The machine ram is driven by an air-cooled linear motor $(28 \mathrm{~kW})$. The system performance-features include a max. frequency of $1000 \mathrm{spm}$, a max. force of $5.3 \mathrm{kN}$, a vertical-position resolution of $0.1 \mu \mathrm{m}$ (tooling), and load-measurement resolution of $0.1 \mathrm{~N}$. The machine system enables the micro-stamping/-forming of sheet-metal parts (strips of 20 to 100 microns thickness). It has a maximum working space of $400 \mathrm{~mm} \times 400 \mathrm{~mm}$, with flexible set-up options. The ram-driving form/power type is changeable, without need of changing other machine set-ups. The force/displacement monitoring system has the capabilities of force measurement with time and displacement with time, and these can be correlated to produce force with distance at the ram and with relative displacement between the punches and the die-sets.

\section{SYSTEM VALIDATION}

The forming of demonstration components (sheetmetal parts) was used to test the forming machine system with newly-developed single-stage and multi-stage stamping tools. For purposes of comparison, basic geometrical forms such as triangles, rectangles, squares and circles, were used for micro-blanking to test different types of 


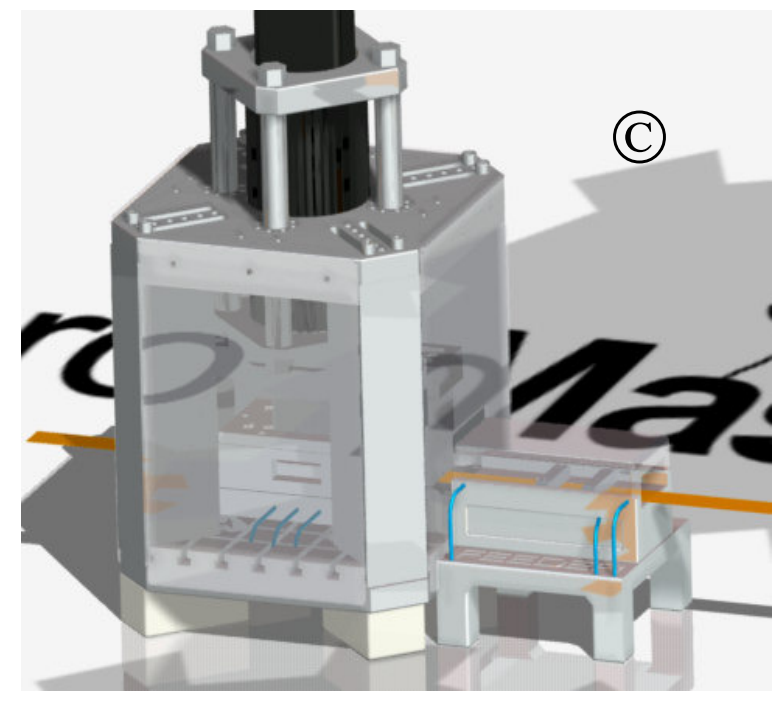

Fig. 4 Model of the machine system for microsheet forming -Flexible- $\mu$-Forming ${ }^{T M}$

materials. A multi-stage tool (a five-stage progressive die design) was developed for the forming of a spring actuator used in a micro-switch, which included the punching, blanking and bending of 25 and $50 \mu \mathrm{m}$ thick sheet metals (hardened and tempered high-carbon steel, temper-rolled stainless steel and temper-rolled brass). Two strips and some of the specimens produced are shown in Fig. 5. The tooling design considered compatibility to the strip feeding, part transport and use of vacuum/compressed air. The machine system was tested at the rates of $60,100,200,300$ and 1000 spm. Process-, tool- and-machine concepts were proven through these tests. A further test - the forming of micro-caps for a micro-packaging system, designed by the MASMICRO consortium (involving punching, blanking, bending and deep drawing) - is being prepared, a focus being also on the improvement of the quality of the parts to be produced.

\section{CONCLUSIONS}

The prototype of a new machine system for microsheet-forming (Flexible- $\mu$-Forming ${ }^{T M}$ ) has been developed, which incorporates a modular design concept. The development is enabled with several innovative designs in tools and material/workpiece handling, with careful consideration of practical usage in an industrial environment. The system ihas been tested with the forming of several demonstration components. The developed machine system can also be used for other microforming processes, with alternative tool designs. A further stage in this development is an industrial design of the machine, led by Fundacion Tekniker, Spain. The design is now available to industrial users.

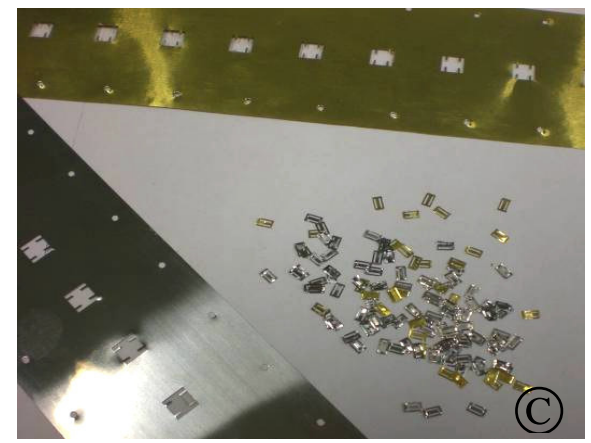

Fig. 5 Two metal strips and samples of the formed parts

\section{ACKNOWLEDGEMENTS}

The support from European Commission for conducting research in the 'Integration of Manufacturing Systems for Mass-manufacture of Miniature/Micro-Products (MASMICRO)' (NMP2-CT-2004-500095) is acknowledged. Shared experience and knowledge with other MASMICRO partners in machine and tool development is particularly acknowledged.

\section{REFERENCES}

1. M. Geiger, M.Kleiner, R.Eckstein, N.Tiesler and U.Engel, "Microforming", Annals of CIRP 50 (2) (2001) 445 462.

2. F. Vollerston, Z. Hu, H. Schulze Niehoff and C. Theiler, State of the art in microforming and investigations into micro-deep drawing. J. Mats. Proc. Tech., 151 (2004) 7079.

3. U. Engel and S. Geißdörfer, "Microforming technology on the way to industrial application", Keynote paper, Proc. 1st Int. Conf. on Micro-Manufacturing, UrbanaChampaign, USA, Sept. 2006, pp. 21-30

4. EU Masmicro Consortium, Project Technical Reports (2004-2007), NMP2-CT-2004-500095.

5. Y. Qin, 'Micro-forming and miniature manufacturing systems - Development needs and perspectives', Keynote paper 11th Int. Conf. of Metal Forming, Sept. 2006, J. Mats. Proc. Tech., 177 (2006) 8-18.

6. Y. Qin, 'Development of an integrated manufacturing facility for mass-manufacture of miniature/microproducts', Keynote paper, Proc. 1st Int. Conf. on MicroManufacturing, Urbana-Champaign, USA, Sept. 2006, pp.35-40.

7. Y. Qin, 'Advance in micro-manufacturing research and technological development, and challenges/opportunities for micro-mechanical machining', Keynote paper, The Cutting Tool Congress 2007, Milan, Nov. 2007, 1-8. 